\title{
Cinética de secagem de amostras de abacaxi (ananas comosus 1.) em secador solar
}

\author{
Drying kinetic of samples (ananas comosus l.) in solar dryer
}

PEDRO VICTOR CRESCÊNCIO DE FREITAS ${ }^{1}$, JOÃO PAULO DO RÊGO BEZERRA TRAVASSOS ${ }^{2}$, LUAH DE ALENCAR ANDRADE ${ }^{3}$, RAUL FELIPE DE QUEIROZ FREITAS ${ }^{4}$, JOSEVÂNIA RODRIGUES JOVELINO ${ }^{5}$, PLUVIA OLIVEIRA GALDINO ${ }^{1}$, JOCIELYS JOVELINO RODRIGUES ${ }^{1}$

\begin{abstract}
RESUMO
As curvas de secagem são excelentes ferramentas de observação do sistema aplicado, de modo a desenvolver processos e dimensionar equipamentos. Já essa metodologia aplicada ao abacaxi permite que haja um acompanhamento das características de desidratação pelo o método aplicado, que foi a secagem solar direta. O objetivo do estudo foi estabelecer curvas de secagem que apresentassem o comportamento de todo o processo quanto a perda de umidade do fruto. As amostras foram submetidas à desidratação com geometrias cubicas com $1 \mathrm{~cm}$ de largura e $1,5 \mathrm{~cm}$ de comprimento, onde foram levadas ao tratamento de branqueamento por 30 segundos. Foram pesadas em uma balança de precisão e levadas ao secador solar. A cada 1 horas, as amostras seguiram para pesagem até apresentar peso constante foram construídas curvas de secagem com o teor de umidade ao longo do tempo de secagem construídas por meio da determinação dos valores da razão da umidade adimensional. Os dados experimentais das curvas de secagem para duas condições foram ajustados ao modelo matemático de secagem baseado na Segunda Lei de Fick. O coeficiente difusivo, obtido através da aplicação da segunda lei de Fick, para a geometria cilíndrica foi de $3,81 \times 10^{-10} \mathrm{~m}^{2} / \mathrm{s}$.
\end{abstract}

Palavras-chave: Secagem Solar; Lei de Fick, Perda de Massa

\begin{abstract}
Drying curves are excellent tools for observing the applied system, in order to develop processes and dimension equipment. On the other hand, this methodology applied to pineapple allows for a monitoring of the dehydration characteristics by the method applied, which was direct sun drying. The objective of the study was to establish drying curves that showed the behavior of the entire process regarding the loss of moisture in the fruit. The samples were subjected to dehydration with cubic geometries $1 \mathrm{~cm}$ wide and $1.5 \mathrm{~cm}$ long, where they were taken to the bleaching treatment for 30 seconds. They were weighed on a precision scale and taken to the solar dryer. Every 1 hour, the samples were weighed until they showed constant weight. Drying curves were constructed with the moisture content over the drying time, constructed by determining the values of the dimensionless moisture ratio. The experimental data of the drying curves for two conditions were fitted to the mathematical model of drying based on Fick's Second Law. The diffusive coefficient, obtained by applying Fick's second law, for the cylindrical geometry was $3.81 \times 10^{-10} \mathrm{~m}^{2} / \mathrm{s}$.
\end{abstract}

Keywords: Solar drying; Fick's Law, Mass Loss 


\section{INTRODUÇÃO}

O abacaxizeiro da espécie Ananas comosus (L.) Merr., é uma planta originária da amazônia, sendo desde a época pré-colombiana cultivada pelos nativos. Segundo a FAO, o Brasil em 2014 obteve área colhida com abacaxi de 66.599 hectares (MATOS, 2014). Essa planta monocotiledônea perene, pertencente à família Bromeliaceae. Seu fruto, o abacaxi, possui grande importância, e seu cultivo vem se expandindo no mundo, principalmente pelo seu sabor, aroma, cor e características físico-químicas (RAMOS et al., 2008).

No Brasil, mais de $90 \%$ do abacaxi produzido é consumido in natura, com perdas ao redor de $10-15 \%$ do produto colhido. Esta perda e a falta de incentivo para sua produção podem ser, em parte, atribuídas à falta de conveniência desta fruta, que exige descasque trabalhoso e com escorrimento de líquido, contenção em vasilhame adequado e utensílios próprios para consumo (MATOS, 2014). Atualmente o nível de informação dos consumidores faz com que eles estejam aptos a se tornarem mais exigentes na aquisição de produtos alimentares de rápido preparo, alto valor nutritivo e excelente qualidade sensorial (MACHADO et al, 2012).

A vida de prateleira de um produto para a sua comercialização é de suma importância, para que não ocorra perda de qualidade, assim é necessário a aplicação de métodos de conservação. A escolha para aplicação do método é fundamental, pois o tipo de processamento aplicado poderá afetar a qualidade do produto. A secagem realizada em frutas é mais empregada e eficaz, mostrando eficiência no aumento da vida de prateleira, permanecendo características inalteradas como o sabor e redução de volume, propiciando sua disponibilidade nos mercados para seu consumo (KEK et al., 2013)

Dessa forma, a desidratação do abacaxi se torna uma maneira de conservação e industrialização dessa fruta. A desidratação osmótica combinada com a secagem solar apresenta-se como um ótimo método de conservação para frutas e, além disto, agrega um bom valor ao produto que pode ser produzido facilmente por pequenos produtores rurais.

A Secagem é uma das técnicas mais antigas de preservação de alimentos utilizadas pelo gomem. O processo é simples e consiste na eliminação de água em um produto por evaporação com transferência de calor e massa. Uma vantagem da secagem é que o alimento processado por essa técnica não necessita de refrigeração durante o armazenamento e transporte (MELONI,2003). 
Existem dois métodos de secagem: a natural, feita pelo sol ou vento (método mais antigo); e a artificial, a qual necessita de fornecimento de energia. As vantagens de se utilizar o processo de secagem são várias, dentre as quais: a facilidade na conservação do produto; a estabilidade dos componentes aromáticos à temperatura ambiente por longos períodos de tempo; a proteção contra degradação enzimática e oxidativa; a redução do peso do produto; a economia de energia por não necessitar de refrigeração e a disponibilidade do produto durante qualquer época do ano (PARK et al., 2001; FEMENIA et al., 2009).

Estudos e análises de curvas de secagem e determinação do teor de água permitem entender e visualizar melhor o processo de secagem, bem como escolher o procedimento, o tratamento, o equipamento e a temperatura adequada para se realizar a desidratação de fruta, para melhor qualidade sensorial e tecnológica (OLIVEIRA et al., 2002).

Neste contexto, o presente estudo, objetivou-se em realizar um estudo do efeito da secagem solar em abacaxi e obter suas curvas cinéticas de secagem.

\section{MATERIAL E MÉTODOS}

O presente estudo foi realizado no Laboratório de Operações Unitárias e Fenômenos de Transporte da Universidade Federal de Campina Grande, campus de Pombal. Foram utilizadas como matéria prima para a secagem abacaxi obtida no próprio campus.

Na Figura 3, encontra-se o fluxograma do experimento na obtenção da fruta de abacaxi seca. As amostras foram submetidas à desidratação em um tipo de corte, em formato de cubos com $1 \mathrm{~cm}$ de largura e $1,5 \mathrm{~cm}$ de comprimento, medidos com o auxílio de um paquímetro, presentes na Figura 4.

Após os cortes, as amostras foram levadas ao tratamento de branqueamento por 30 segundos em água fervente e 30 segundos em água gelada. Em seguida, foram pesadas em uma balança de precisão e levadas ao secador solar. A cada 1 horas, as amostras seguiram para pesagem até apresentar peso constante. Com o resultado da obtido da secagem, cerca de 5 gramas de amostras foram levados a estufa, por 24 horas, com finalidade de determinar o teor de umidade final segundo a Metodologia do Instituto Adolf Lutz (2008).

Semelhante ao processo de secagem realizado, a fim de obter o teor de umidade final. Foi realizado a medição de 3 amostras pesando cerca de $5 \mathrm{~g}$, onde foram levadas 
para estufa à temperatura de aproximadamente $107^{\circ} \mathrm{C}$ por 24 horas, de modo a se obter a umidade de equilíbrio.

Figura 1- Fluxograma do processo de secagem e obtenção do teor de umidade

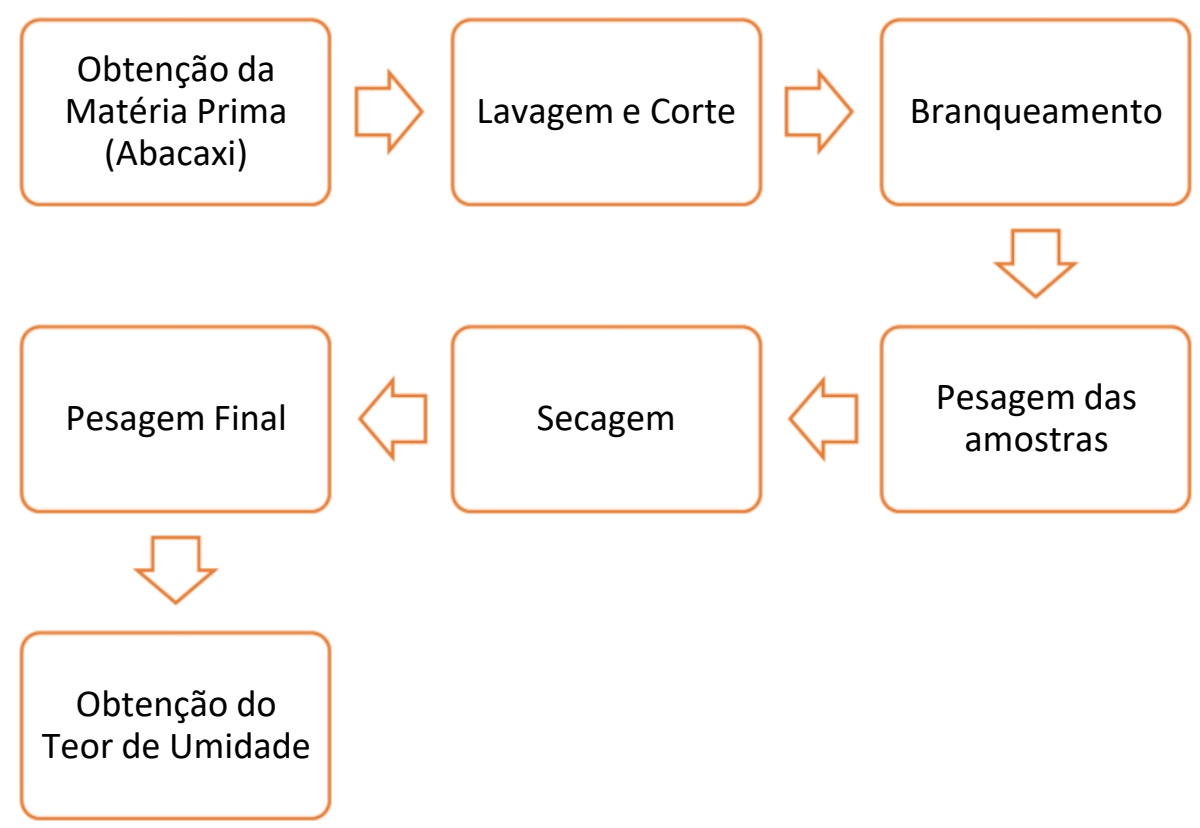

Fonte: CRESCENCIO, 2019

Com relação a cinética de secagem dos abacaxis, foram construídas curvas de secagem com o teor de umidade ao longo do tempo de secagem, indicando o comportamento da redução do conteúdo de umidade do fruto analisado. As curvas de secagem foram construídas por meio da determinação dos valores da razão da umidade adimensional $\left(\mathrm{X}^{*}\right)$ versus o tempo de secagem, conforme mostra a Equação 1.

$$
X^{*}=\frac{X_{\text {tempo }}-X_{e q}}{X_{\text {inicial }}-X_{e q}}
$$

Onde: Xtempo é a umidade da amostra ao longo da secagem (g); Xinicial é a umidade inicial da amostra; Xeq é a umidade da amostra após atingir o equilíbrio.

Os dados experimentais para a curva de secagem foram ajustados ao modelo matemático de secagem baseado na Segunda Lei de Fick, representando pela Equação 3, onde o estudo do coeficiente de difusão na secagem de frutas é realizado para transferência de massa e da equação da continuidade, com a finalidade de descrever a 
transferência de massa com fluxo de líquido do interior do abacaxi, levando em consideração os períodos de secagem, as geometrias fruta, resistência interna desprezível, encolhimento/não encolhimento do material e que o processo é controlado por difusão interna.

Transferência de massa é um fenômeno ocasionado pela diferença de concentração, maior para menor, de um determinado soluto em certo meio (INCROPERA et al.; 2008).

A equação da continuidade mássica apresentada na equação (2) representa a variação da concentração mássica, $\rho_{\mathrm{A}}$, fruto do movimento de $\mathrm{A}$ e da sua produção ou consumo (CREMASCO, 2008; INCROPERA et al.; 2008).

$$
\frac{\partial \rho_{A}}{\partial t}+\frac{\partial \rho_{B}}{\partial t}+\nabla \cdot \vec{n}_{A}+\nabla \cdot \vec{n}_{B}=r_{A}^{\prime \prime}+r_{B}^{\prime \prime \prime}
$$

A Segunda Lei de Fick descreve os processos difusivos em estado não estacionário, Crank (1975) propôs um ajuste experimental, considerando a razão de umidade para placas planas, conforme apresentado na equação 3:

$$
\frac{X_{t}-X_{e}}{X_{0}-X_{e}}=\frac{8}{\pi^{2}} \sum_{i=0}^{\infty} \frac{1}{(2 i+1)^{2}} \exp \left[-(2 i+1)^{2} \pi^{2} D_{e f} \frac{t}{4 L^{2}}\right]
$$

onde: $X_{t}=$ umidade em um determinado tempo $X_{o}=$ umidade inicial $(\mathrm{kg} / \mathrm{kg} \mathrm{ms}) ; \mathrm{X}_{\mathrm{e}}=$ umidade no equilíbrio $(\mathrm{kg} / \mathrm{kg} \mathrm{ms})$; Def = difusividade efetiva $\left(\mathrm{m}^{2} / \mathrm{s}\right) ; \mathrm{L}=$ meia espessura $(\mathrm{m}) ; \mathrm{t}=$ tempo de processo.

E para a geometria cilíndrica, Brooker (1992) apresenta a solução analítica (equação 4):

$$
\frac{X_{t}-X_{e}}{X_{o}-X_{e}}=\sum_{n=1}^{\infty} \frac{4}{\lambda_{n}^{2}} \exp \left[-\frac{\lambda_{n}^{2} \cdot D \cdot t}{r}\right]
$$

em que $r=$ raio equivalente $(\mathrm{m})$. (CREMASCO, 2008).

Os encolhimentos dos frutos foram observados ao longo de todo o processo de secagem, e mensurado por meio de análise de imagens, onde as amostras foram colocas 
sempre em uma mesma distância e posição para captura das imagens mantendo a máxima de simetria para avaliação.

A partir dos resultados da massa de sólido úmido a serem obtidos nos tempos pré-determinados ao longo da cinética de secagem, determina-se o teor de umidade das amostras, em base seca (bs) e em base úmida (bu) definido pelas equações (5).

$$
X_{b s}=\frac{m_{s s}-m_{s u}}{m_{s s}} \quad X_{b u}=\frac{X_{b s}}{1+X_{b s}}
$$

\section{RESULTADOS E DISCUSSÃO}

Observa-se na Figura 2, o comportamento dos frutos de abacaxi ao serem submetidos a secagem solar, onde a mesma teve duração de $14 \mathrm{hrs} \mathrm{de} \mathrm{secagem.} \mathrm{Na} \mathrm{Figura}$ 2 (a) encontra-se o período inicial, onde o fruto foi cortado e colocado sobre as bandejas, e Figura 2 (b) com 14 horas de secagem.

Figura 2- Amostras de abacaxi tempo inicial (a) e tempo final com 14hrs de secagem (b).

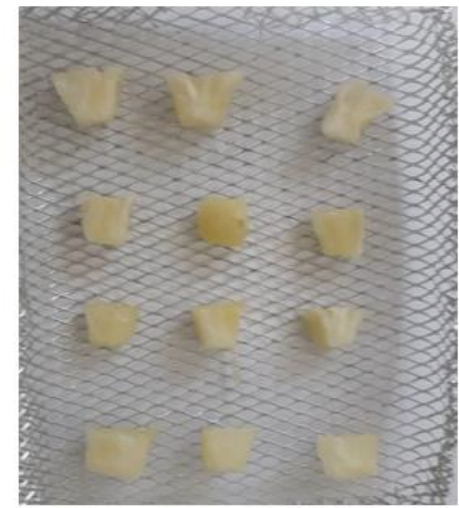

(a)

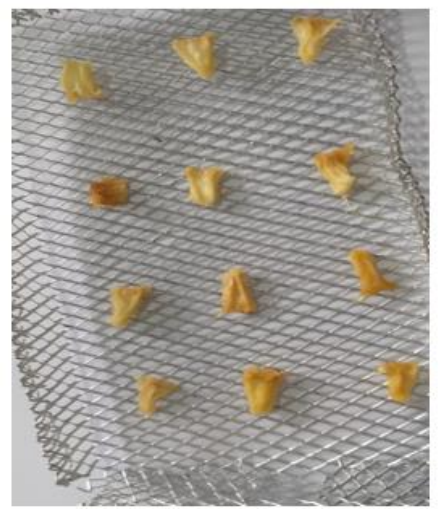

(b)

Nota-se que o formato o qual os abacaxis foram cortados contribuiu para uma secagem rápida, onde essas características mostram que durante a cinética de secagem possa ter ocorrido diferentes mecanismos de transporte de calor e massa. Além da redução do volume, a secagem conferiu coloração característica às amostras, possivelmente devido à concentração de solutos e à reação de Maillard (CELESTINO, 2010).

Na Figura 3 encontram-se os gráficos da redução de massa em base úmida e seca, ao longo do período das análises.

Figura 3- Redução em base úmida (a) e em base seca (b) 


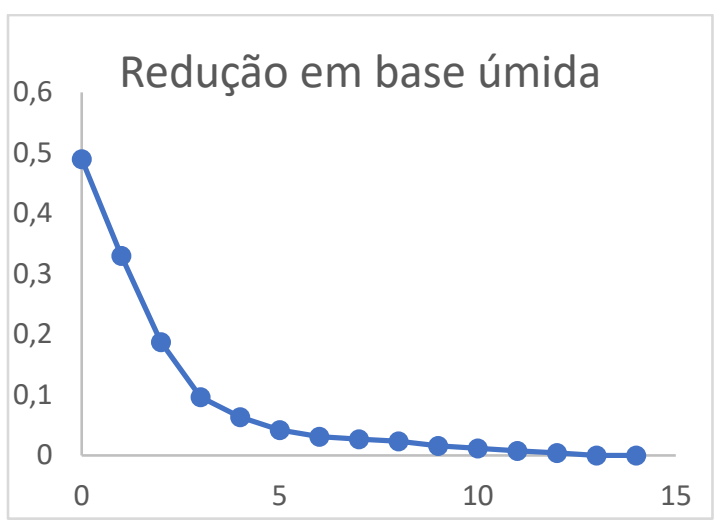

(a)

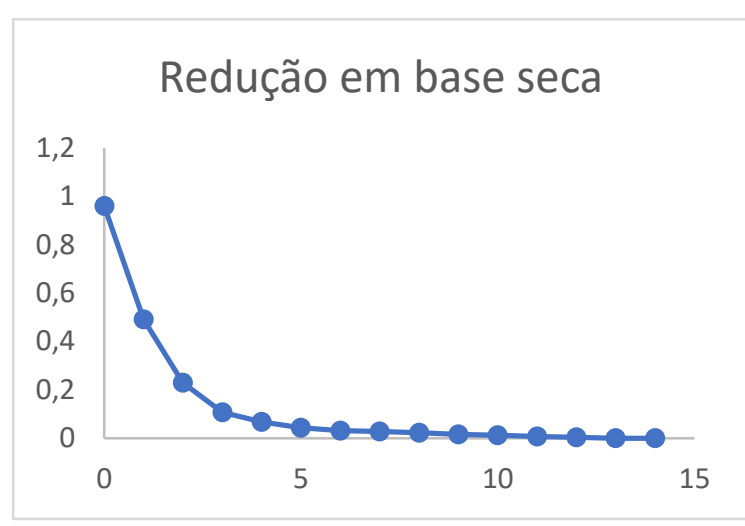

(b)

Nota-se que a geometria utilizada proporcionou uma boa velocidade de secagem pela transferência de massa.

Na Figura 4 encontram-se os gráficos com relação ao decrescimo da umidade em massa e em percentual ao longo do período de secagem.

Geralmente no início do processo de secagem solar existe um maior fluxo de ar a circular dentro do secador para remover a água livre dos alimentos em secagem. Um decréscimo do fluxo de ar na entrada do colector, provoca um aumento da temperatura do ar dentro do colector e uma ligeira diminuição da humidade do ar dentro do secador (DIAS, 2017).

Figura 4- Decrescimo da umidade em massa (a) e em percentual

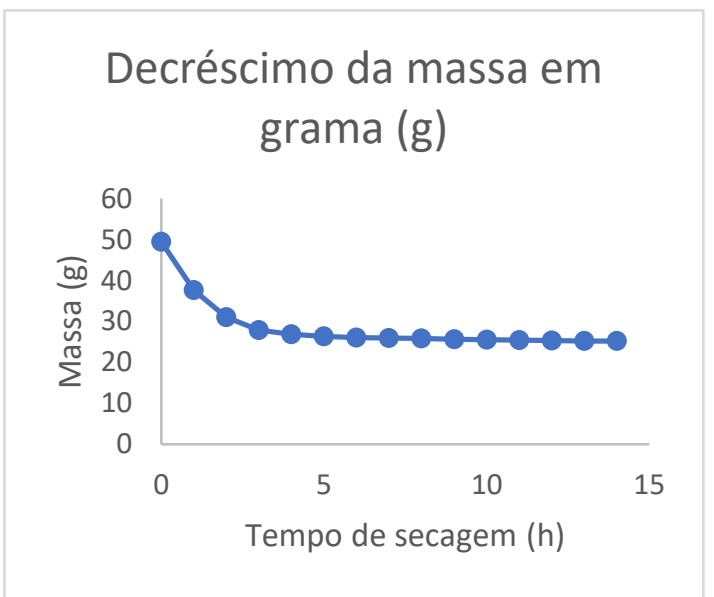

(a)

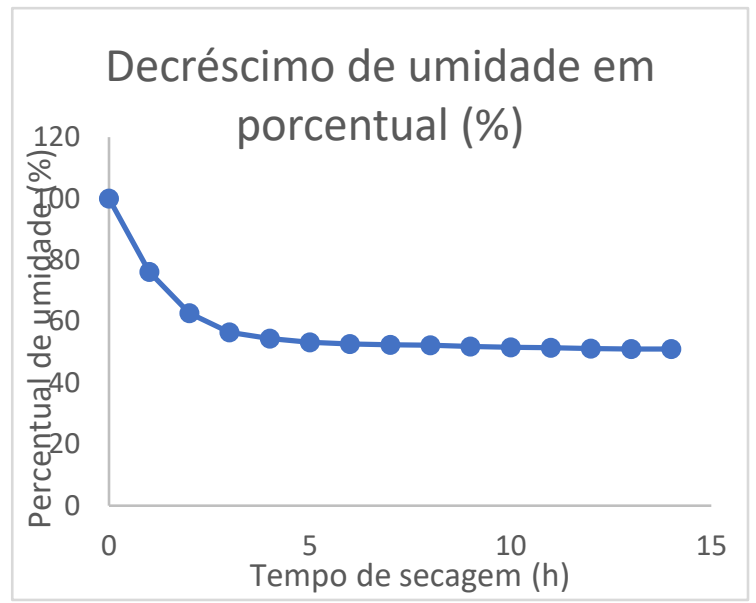

(b)

Ao observar a perda de massa, nota-se que nas primeiras horas há um decréscimo mais acentuado, e esse episódio está diretamente relacionado à umidade de superfície, que se refere a eliminação da água livre contida no alimento, pouco ligada aos substratos 
do alimento. A partir da quarta hora, nota-se uma perda mais branda e isso ocorre pela difuldade de perda da água do interior da amostra. Esse decréscimo cessa quando a umidade entra em equilíbrio entre o fruto e o ambiente em que ela estava presente.

Na Figura 5 encontra-se o ajuste das condições aplicadas à Segunda Lei de Fick em geometria plana em fruta de abacaxi.

Ajustando o modelo matematico e aplicando-o ao programa Statistica 10, obtivese o coeficiente difusivo, obtido através da aplicação da segunda lei de Fick, para geometria plana adotada, contando valor de $3,81 \times 10^{-10} \mathrm{~m}^{2} / \mathrm{s}$.

Silva et al. (2016) ao avaliarem a modelagem da cinética de secagem solar da fruta mangaba, utilizam também da segunda lei de Fick e obteve valores de 1,34 x $10^{-10}$ e 6,49 x $10^{-11} \mathrm{~m}^{2} / \mathrm{s}$, para o coeficiente de difusão em seus tratamentos valores próximos ao do presente trabalho. Esses resultados semelhantes podem dar a alusão na eficiência matemática da segunda lei de Fick para secagem de frutas.

Figura 5 - Ajuste das condições aplicadas à Segunda Lei de Fick em geometria plana em fruta de abacaxi.

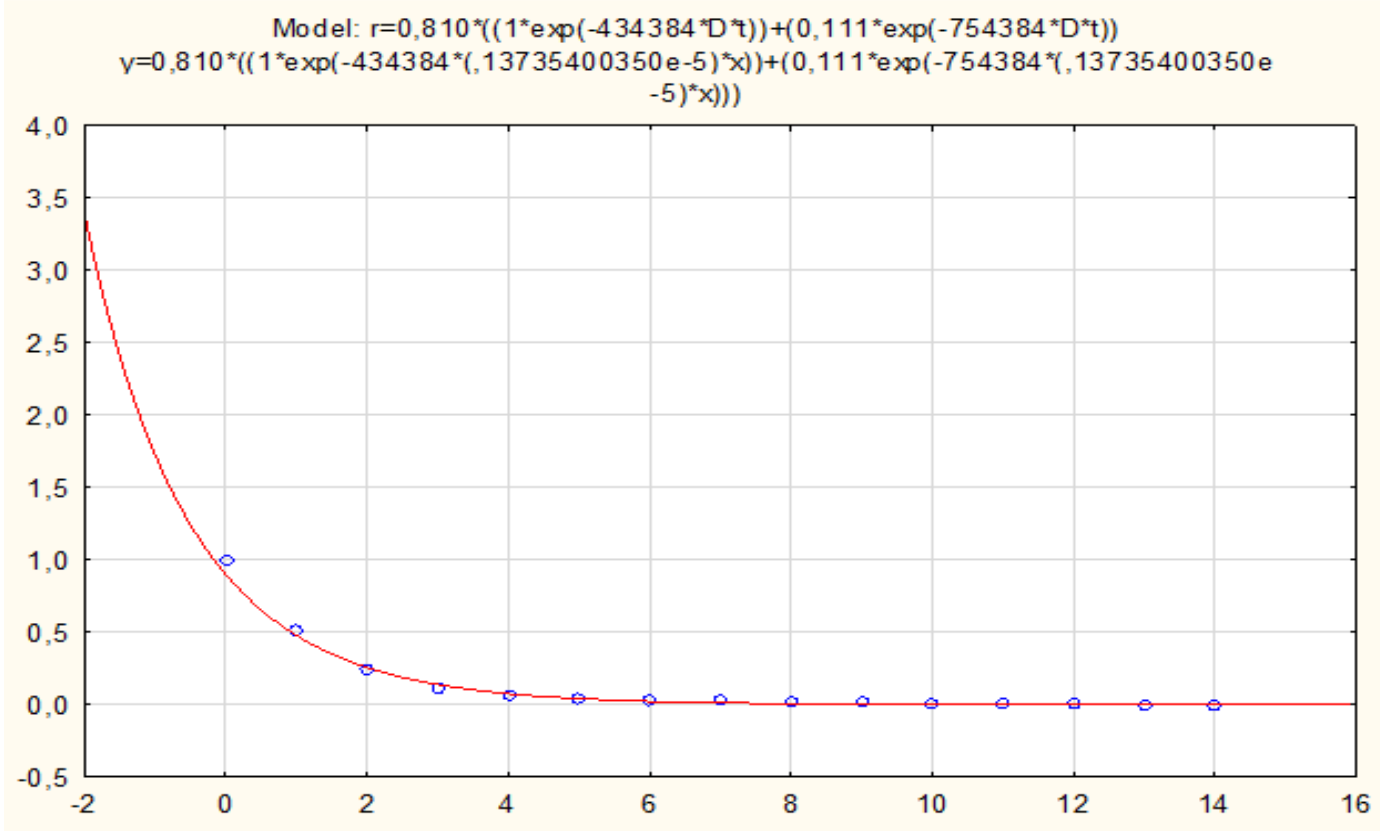

$\mathrm{R}=0,99360$ Varieance Explained 98,724\% 


\section{CONCLUSÕES}

O abacaxi é um fruto com uma grande quantidade de água. O coeficiente de difusão foi de $3,81 \times 10^{-10} \mathrm{~m}^{2} / \mathrm{s}$, onde na literatura consta que o tipo de geometria utilizada apresenta mais eficiência com relação à secagem do fruto, levando menos tempo para atingir um ponto de pesagem estável, devido ao seu baixo coeficiente de difusão.O processo de secagem é uma alternativa mais econômica para secagem de frutos.

\section{REFERÊNCIAS}

CELESTINO, S. M. C. Princípios de secagem de alimentos. Planaltina, DF: Embrapa Cerrados, 2010.

CRANK, John. The Mathematics of Diffusion: Ed. Oxford, Bristol,1975.

CREMASCO, M. A. Fundamentos de transferência de massa. Editora Unicamp, São Paulo, 2008.

DIAS, A. M. S. M. R. Secagem solar como técnica para reduzir as perdas pós-colheita dos pequenos produtores: Construção de um secador solar indireto a partir de materiais reutilizados. Dissertação (Mestrado em Engenharia Agronômica) - Universidade de Lisboa, Lisboa. 2017.

FEMENIA, A.; SERRANO, G.S.; SIMAL, S.; GARAU, M.C.; EIM, V.S.; ROSSELLÓ, C. Effects of air-drying temperature on the cell walls of kiwifruit processed at different stages of ripening. Food Science and Technology. v. 42, n. 1, p. 106-112, 2009.

INCROPERA, F. P.; DEWITT, D. P.; BERGMAN, T. L.; LAVINE, A. Fundamentos de transferência de calor e de massa. Editora LTC, Rio de Janeiro, 2008.

KEK, S. P.; CHIN, N. L.; YUSOF, Y. A. Direct and indirect power ultrasound assisted preosmotic treatments in convective drying os guava slices. Food and Bioproducts Processing, v. 91, p. 495-506, 2013.

MACHADO, A. M. Cinéticas de secagem do abacaxi cv. Pérola. Enciclopédia biosfera, centro científico conhecer, Goiânia, v.8, n.15 p.428, 2012.

MATOS, A. P.; VASCONCELOS, J. A. R.; SIMÃO, A. H. Práticas de Cultivo para a Cultura do Abacaxi no Estado do Tocantins. 2014

MELONI, P. L. S. Desidratação de frutas e hortaliças. Fortaleza: Instituto Frutal, 2003. $87 \mathrm{p}$.

OLIVEIRA, L. F.; NASCIMENTO, M.R.F.; BORGES, S.V.; RIBEIRO, P.C.N.; RUBACK, V.R. Aproveitamento alternativo da casca do maracujá-amarelo (Passiflora edulis F. flavicarpa) para produção de doce em calda. Ciência e Tecnologia de Alimentos. v. 22, n. 3, p. 254-258, 2002.

PARK, K. J.; YADO, M. K. M.; BROD, F. P. R. Estudo de secagem de pêra bartlett (Pyrus sp.) em fatias. Ciência e Tecnologia de Alimentos. v. 21, n. 3, p. 288-292, 2001.

RAMOS, A.M.; QUINTERO, A.C.F.; FARAONI, A.S.; SOA.RES, N.F.F.; PEREIRA, J.A.M. Efeito do tipo de embalagem e do tempo de armazenamento nas qualidades físicoquímica e microbiológica de abacaxi desidratado. Alimentos e Nutrição. v.19, n.3, p. 259-269, jul./set. 2008. 
SILVA, A.L.; NETO, J. R. A.; SANTO, V. C. S.; SILVA, G. F.; MONTEIRO, L. F.; A. S. LIMA, A. S.; ALSINA, O. L. S. Modelagem da cinética da secagem solar da mangaba (Hancornia speciosa) considerando os efeitos do encolhimento. XXV Congresso Brasileiro de Ciência e Tecnologia de Alimentos. 2016.

Recebido em: 01/09/2021

Aprovado em: 25/09/2021

Publicado em: 30/09/2021 